\title{
Characterization of Miniature Millimeter-Wave Vivaldi Antenna for Local Multipoint Distribution Service
}

Rainee N. Simons

NYMA, Inc.

Brook Park, Ohio

and

Richard Q. Lee

Lewis Research Center

Cleveland, Ohio

Prepared for the

49th Automatic RF Techniques Group Conference

cosponsored by the Institute of Electrical and Electronics Engineers

and the Microwave Theory and Techniques Society

Denver, Colorado, June 13, 1997

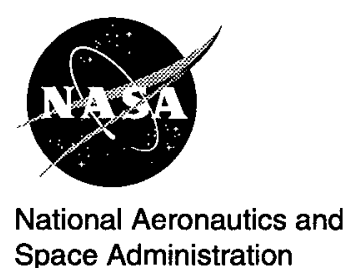




\title{
CHARACTERIZATION OF MINIATURE MILLIMETER-WAVE VIVALDI ANTENNA FOR LOCAL MULTIPOINT DISTRIBUTION SERVICE
}

\author{
Rainee N. Simons \\ NYMA, Inc. \\ Brook Park, Ohio 44142 \\ Tel:(216)433-3462 Fax:(216)433-8705 \\ Email:Rainee.N.Simons@lerc.nasa.gov \\ Richard Q. Lee \\ National Aeronautics and Space Administration \\ Lewis Research Center \\ Cleveland, Ohio 44135
}

\begin{abstract}
The paper presents first, an efficient measurement technique to characterize the input impedance of a Vivaldi antenna, second, a simple technique to impedance match a Vivaldi antenna to a $50 \Omega$ feed line and lastly, a desktop arrangement to determine the directional gain of a Vivaldi antenna. The characterization is done using a microwave wafer probe station, a ground-signal microwave probe, impedance standard substrate and an automatic network analyzer. The Vivaldi antenna with a matching transformer has a VSWR close to unity and a gain of about $10 \mathrm{~dB}$ over the frequency band of 27.5 to $28.35 \mathrm{GHz}$ which is allocated for local multipoint distribution service (LMDS).
\end{abstract}

\section{INTRODUCTION:}

The Vivaldi antenna is a very useful antenna because of its simple construction, wide bandwidth and high gain [1]. In general, the Vivaldi antenna has an end-fire radiation pattern. However recently, we have demonstrated that by placing a ground plane and a parasitic antenna layer below and above the driven antenna layer respectively, the direction of main beam can be scanned in the elevation plane [2]. This arrangement is attractive for local multipoint distribution service (LMDS) in residential areas were it is necessary for the antenna to conform to the roof surface for aesthetics while the beam is required to point towards the sky for good line-of-sight propagation.

The Vivaldi antenna being a slot type travelling wave antenna is normally excited by a slot line. Hence for characterization a coax-to-microstrip-to-slot line transition [3] or a waveguide-to-fin line transition is required at the input to interface the antenna with the coaxial or waveguide test equipment. These transitions introduce additional loss and uncertainty in the measurements. In addition, the directional gain of an antenna is normally measured using an antenna test range. Conventional antenna test ranges are very expensive and hence a low cost desktop alternative to provide a quick and approximate measure of the gain needs to be explored. This paper demonstrates an accurate measurement technique to determine the input impedance and an approximate technique to determine the directional gain of a Vivaldi antenna using a microwave wafer probe station, a ground-signal microwave probe, impedance standard substrate and an automatic network analyzer.

\section{VIVALDI ANTENNA:}

\section{a.) Construction:}

Figure 1 illustrates the layout of a typical Vivaldi antenna. The antenna is excited by a slot line. The taper profile is designed according to the equation

$$
\mathrm{x}=(\mathrm{az}+\mathrm{b}) * \exp (\mathrm{mz})
$$




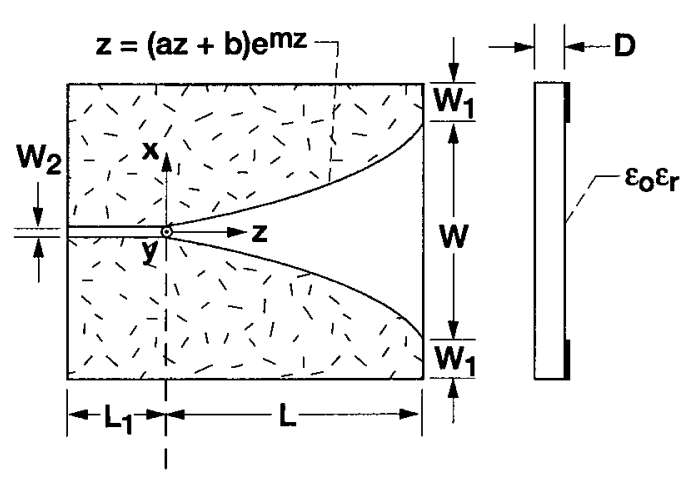

Figure 1.-Schematic of the Vivaldi antenna. $L=25.0 \mathrm{~mm} . \mathrm{L}_{1}=3.175 \mathrm{~mm} . \mathrm{W}=4.44 \mathrm{~mm}$. $W_{1}=3.175 \mathrm{~mm}$. $D=0.01 \mathrm{~mm} . \varepsilon_{r}=10.5$.

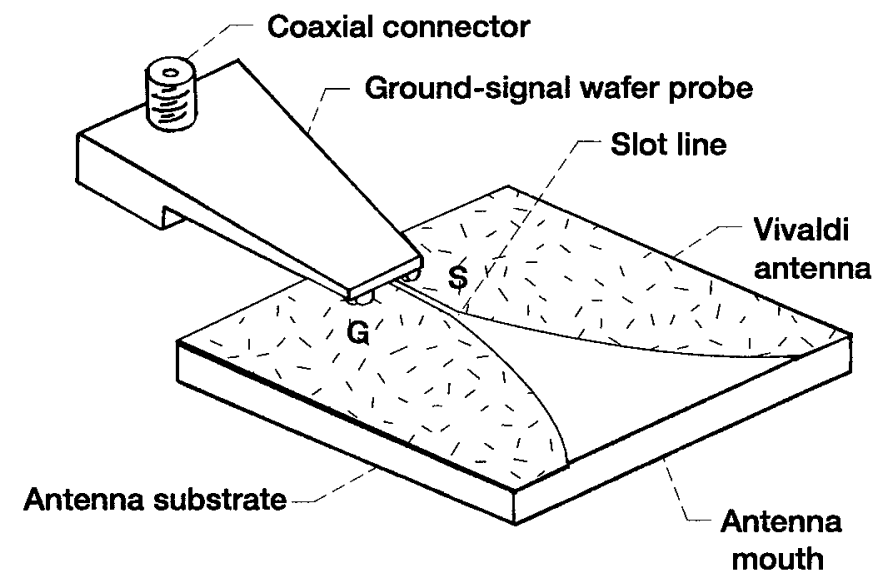

Figure 2.-Experimental set-up for characterizing Vivaldi antenna.

Where $\mathrm{a}, \mathrm{b}$ and $\mathrm{m}$ are constants and are equal to $0.0518,0.005$ and 0.2 respectively. The antenna is fabricated from a 10 mil thick RT/Duroid $6010.5\left(\varepsilon_{\mathrm{r}}=10.5\right)$ substrate. Traditionally antennas are constructed from low $\varepsilon_{\mathrm{r}}$ materials however in our experiments we have used a high $\varepsilon_{\mathrm{r}}$ material which helps to miniaturize the antenna.

\section{b.) Measurement Methodology:}

The Vivaldi antenna is excited by a ground-signal microwave probe (Picoprobe Model 40A) as shown in Fig. 2. During measurements the antenna is supported by a styrofoam block and the metal fixtures of the probe station are covered by microwave absorber sheet to reduce interference. The ground-signal probe is calibrated to the tip using an open, short and a load as a standard. The reflection coefficient $\left(S_{11}\right)$ is measured using a HP 8510C automatic network analyzer. 
To measure the directional gain G, a pair of identical Vivaldi antennas excited by two calibrated ground-signal microwave probes are arranged facing each other and separated by a distance $R$. The distance $R$ is equal to or greater than

$$
\mathrm{R}=2 * \mathrm{D}_{1}^{2} / \lambda_{0}
$$

Where $D_{1}$ and $\lambda_{0}$ are the aperture dimension of the vivaldi antenna and the free space wavelength at the operating frequency respectively. The insertion loss $\left(S_{21}\right)$ due to separation between the antennas is measured using the network analyzer assuming no polarization loss. The gain is given by Friis equation

$$
\mathrm{G}_{\mathrm{r}} \mathrm{G}_{\mathrm{t}}=\mathrm{G}^{2}=\left(\mathrm{P}_{\mathrm{r}} / \mathrm{P}_{\mathrm{t}}\right) *\left(4 \pi \mathrm{R} / \lambda_{0}\right)^{2} \text {. }
$$

Where the power ratio $P_{r} / P_{t}$ is the measured $S_{21}$ and $G_{r}$ and $G_{t}$ are the gain of the receiving and transmitting antennas respectively. The gain of both antennas are identical and is equal to $G$.

\section{MEASURED RESULTS:}

\section{a.) Input Impedance:}

The conventional Vivaldi antenna has a very high input impedance and consequently a poor VSWR characteristic. This problem is tackled by providing a two step dielectric transformer as shown in Fig. 3. The de-embedded real and imaginary parts of the input impedance $\left(\operatorname{Re}\left(Z_{\text {in }}\right)\right.$ and $\left.\operatorname{Im}\left(Z_{\text {in }}\right)\right)$ from the measured $S_{11}$ with and without the dielectric transformer are shown in Figs. 4(a) and 4(b) respectively. The $\operatorname{Re}\left(Z_{\text {in }}\right)$ and $\operatorname{Im}\left(Z_{\text {in }}\right)$ are close to $50 \Omega$ and $0 \Omega$ respectively with a dielectric transformer. The measured VSWR of the antenna with and without the transformer is shown in Fig. 5. The VSWR is close to unity with the transformer.

\section{b.) Directional Gain:}

The experimental set-up to measure gain is shown in Fig. 6. The gain as determined from the measured $S_{21}$ is shown in Fig. 7. Since, the aperture size in wavelengths increases with frequency, the gain also increases with frequency. The gain for a single element is on the order of $10 \mathrm{~dB}$ which is typical of a Vivaldi antenna. To evaluate the accuracy of our measurement technique, we plan to compare the gain obtained using our technique with the data from an antenna test range and also from numerical simulation. These results will be presented at the conference.

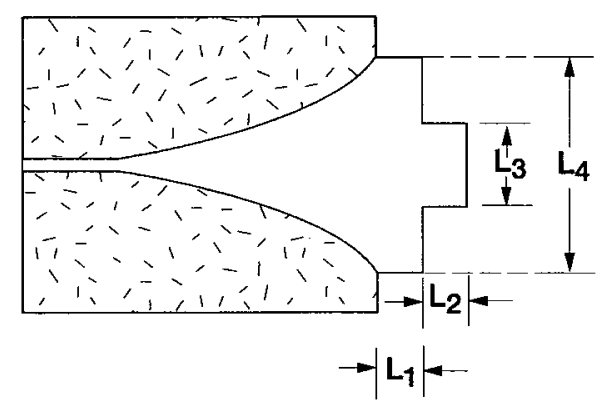

Figure 3.-Vivaldi antenna with a dielectric impedance matching transformer. $\mathrm{L}_{1}=4 \mathrm{~mm}, \mathrm{~L}_{2}=4 \mathrm{~mm}, \mathrm{~L}_{3}=5 \mathrm{~mm}$, $\mathrm{L}_{4}=10 \mathrm{~mm}$. 

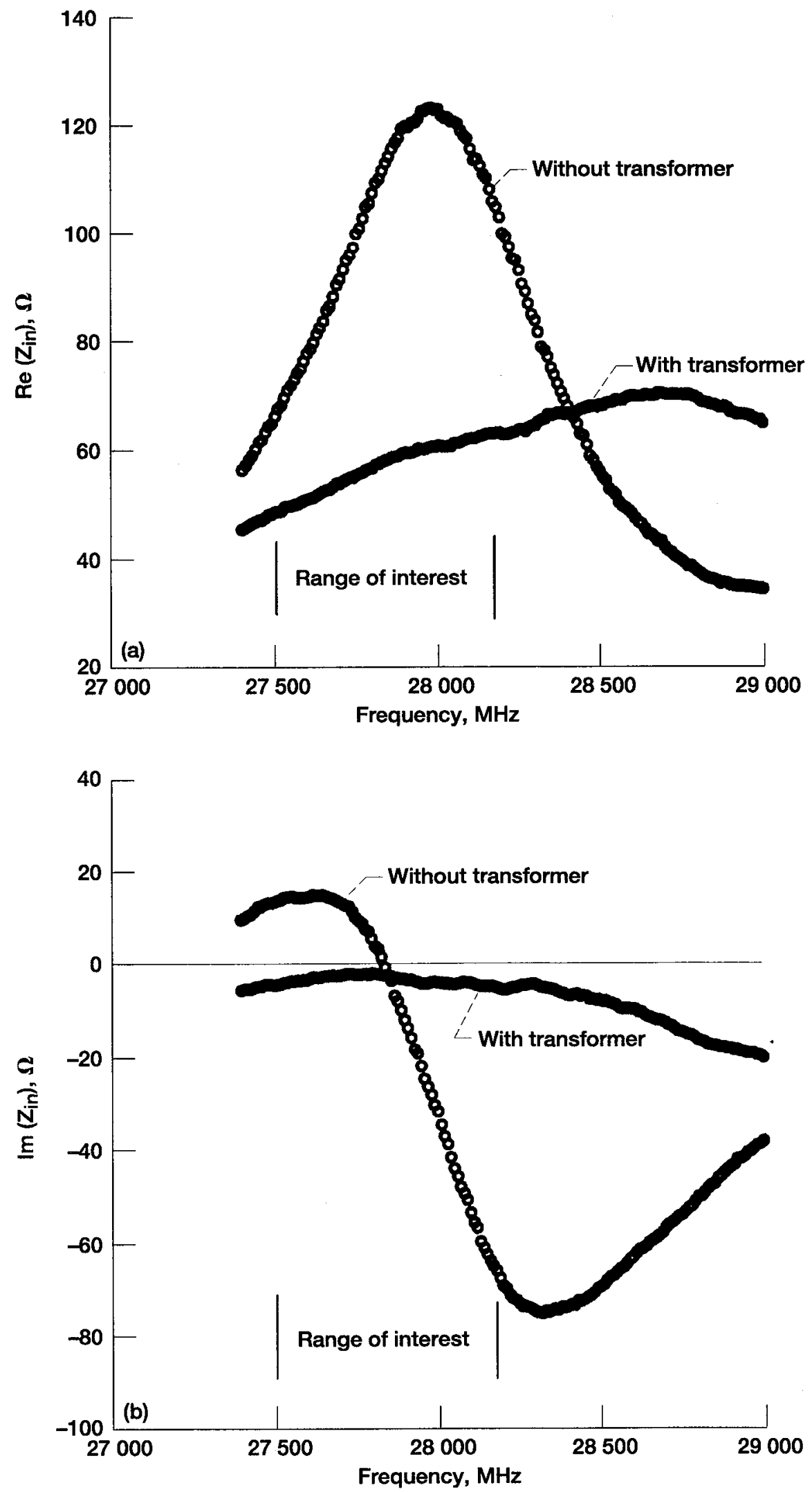

Figure 4.-Real and imaginary part of the input impedance. (a) Real. (b) Imaginary. 


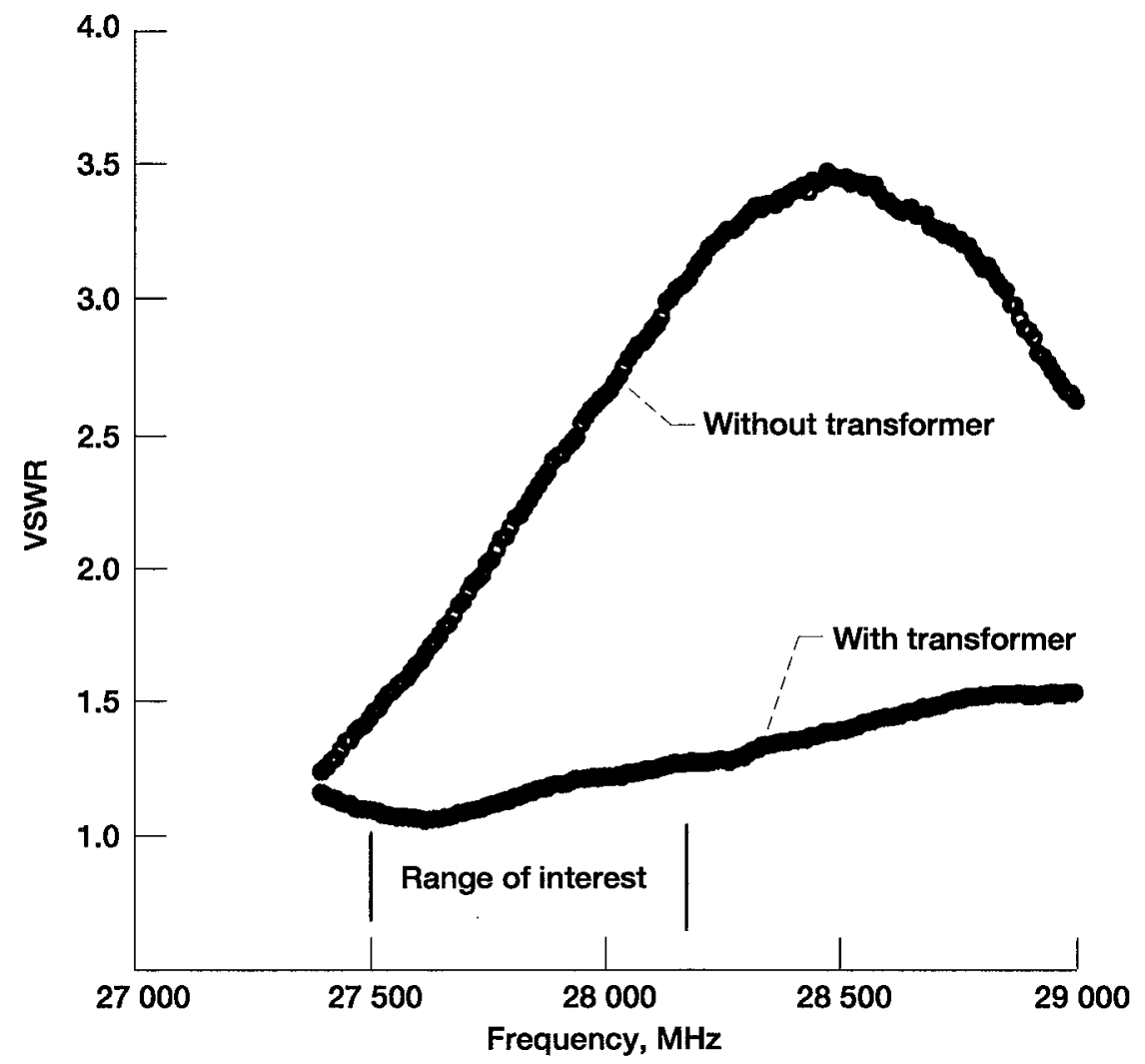

Figure 5.-Input VSWR of the Vivaldi antenna with and without a dielectric transformer.

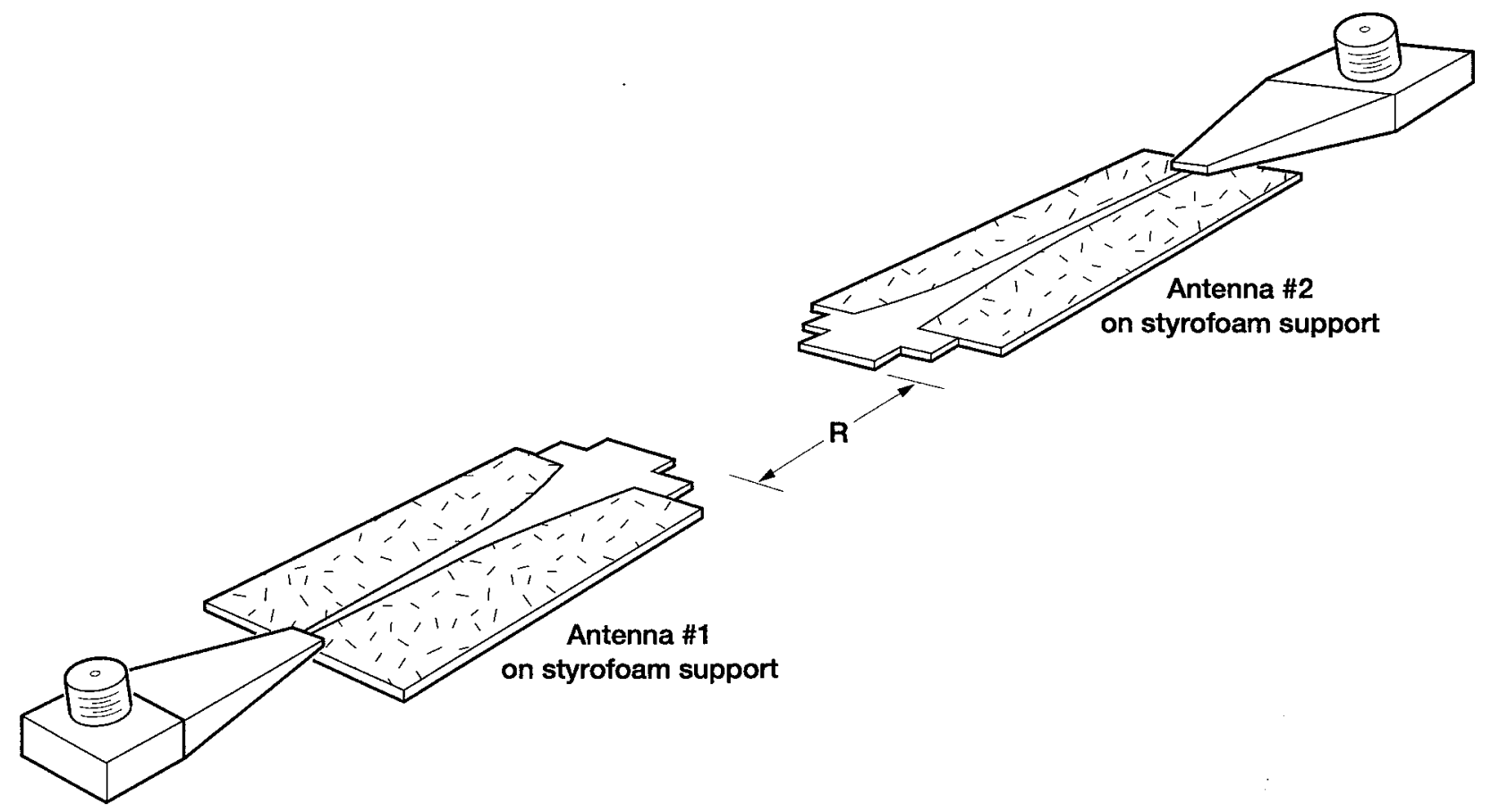

Figure 6.-Experimental set-up for measuring gain. 


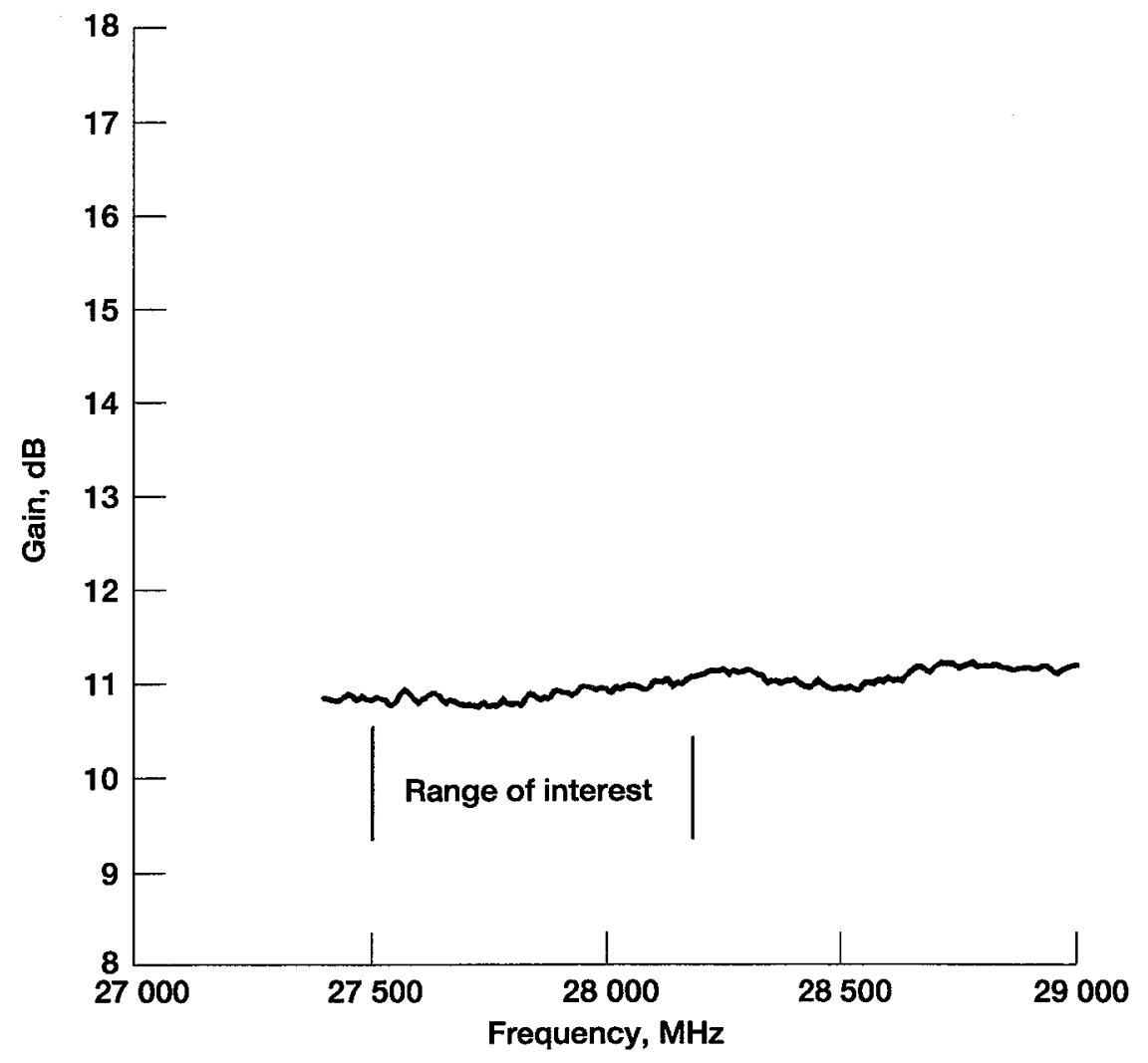

Figure 7.-Measured gain of the Vivaldi antenna.

\section{CONCLUSIONS AND DISCUSSIONS:}

First, an efficient measurement technique to determine the input impedance of a Vivaldi antenna has been demonstrated. Second, a simple technique to impedance match a Vivaldi antenna to a $50 \Omega$ feed line has been demonstrated. Third, a desktop arrangement to determine the directional gain of a Vivaldi antenna has been demonstrated. The Vivaldi antenna has a VSWR close to unity and a gain of about $10 \mathrm{~dB}$ over the frequency band allocated for LMDS.

\section{REFERENCES}

[1] R.Q. Lee and R.N. Simons, Tapered Slot Antenna, in Advances in Microstrip and Printed Antennas, Chap. 9, Ed: K.F. Lee and W. Chen, John Wiley \& Sons, Inc., New York, 1997.

[2] R.N. Simons, E.S. Kelly, R.Q. Lee and S.R. Taub, "Radial Microstrip Slotline Feed Network for Circular Mobile Communications Array," 1994 IEEE Antennas and Propagation Society Inter. Symp. and Radio Science Meeting, Vol.2, pp. 1024-1027, June 1994.

[3] N.I. Dib, R.N. Simons and L.P.B. Katehi, "Uniplanar Microstrip Line to Slot Line Transitions," 1995 IEEE MTT-S Inter. Microwave Symp. Dig., Vol. 2, pp. 683-686, May 1995. 
- 
Public reporting burden for this collection of information is estimated to average 1 hour per response, including the time for reviewing instructions, searching existing data sources, gathering and maintaining the data needed, and completing and reviewing the collection of information. Send comments regarding this burden estimate or any other aspect of this collection of information, including suggestions for reducing this burden, to Washington Headquarters Services, Directorate for Information Operations and Reports, 1215 Jefferson Davis Highway, Suite 1204, Arlington, VA 22202-4302, and to the Office of Management and Budget, Paperwork Reduction Project (0704-0188), Washington, DC 20503.

\begin{tabular}{|r|r|}
\hline 1. AGENCY USE ONLY (Leave blank) & 2. REPORT DATE \\
April 199
\end{tabular}

April 1997

4. TITLE AND SUBTITLE

Characterization of Miniature Millimeter-Wave Vivaldi Antenna for Local Multipoint Distribution Service

6. AUTHOR(S)

Rainee N. Simons and Richard Q. Lee

7. PERFORMING ORGANIZATION NAME(S) AND ADDRESS(ES)

National Aeronautics and Space Administration

Lewis Research Center

Cleveland, Ohio 44135-3191

9. SPONSORING/MONITORING AGENCY NAME(S) AND ADDRESS(ES)

National Aeronautics and Space Administration

Washington, DC 20546-0001

\section{REPORT TYPE AND DATES COVERED}

Technical Memorandum
5. FUNDING NUMBERS

WU-632-50-5B
8. PERFORMING ORGANIZATION REPORT NUMBER

E-10716

10. SPONSORING/MONITORING AGENCY REPORT NUMBER

NASA TM-107445

11. SUPPLEMENTARY NOTES

Prepared for the 49th Automatic RF Techniques Group Conference cosponsored by the Institute of Electrical and Electronics Engineers and the Microwave Theory and Techniques Society, Denver, Colorado, June 13, 1997. Rainee N. Simons, NYMA, Inc., 2001 Aerospace Parkway, Brook Park, Ohio 44142 (work funded by NASA Contract NAS3-27186); and Richard Q. Lee, NASA Lewis Research Center. Responsible person, Rainee N. Simons, organization code 5640, (216) 433-3462.

\begin{tabular}{|l|l}
\hline 12a. DISTRIBUTION/AVAILABILITY STATEMENT & 12b. DISTRIBUTION CODE
\end{tabular}

Unclassified - Unlimited

Subject Category 33

This publication is available from the NASA Center for AeroSpace Information, (301) 621-0390.

13. ABSTRACT (Maximum 200 words)

The paper presents first, an efficient measurement technique to characterize the input impedance of a Vivaldi antenna, second, a simple technique to impedance match a Vivaldi antenna to a $50 \mathrm{~W}$ feed line and lastly, a desktop arrangement to determine the directional gain of a Vivaldi antenna. The characterization is done using a microwave wafer probe station, a ground-signal microwave probe, impedance standard substrate and an automatic network analyzer. The Vivaldi antenna with a matching transformer has a VSWR close to unity and a gain of about $10 \mathrm{~dB}$ over the frequency band of 27.5 to 28.35 GHz which is allocated for local multipoint distribution service (LMDS).

14. SUBJECT TERMS 15. NUMBER OF PAGES 08

Antenna; Vivaldi antenna; Millimeter-waves; Multipoint distribution service 16. PRICE CODE

$\mathrm{A02}$

\begin{tabular}{|c|c|c|}
\hline $\begin{array}{c}\text { 17. SECURITY CLASSIFICATION } \\
\text { OF REPORT } \\
\text { Unclassified }\end{array}$ & $\begin{array}{c}\text { 18. SECURITY CLASSIFICATION } \\
\text { OF THIS PAGE } \\
\text { Unclassified }\end{array}$ & $\begin{array}{c}\text { 19. SECURITY CLASSIFICATION } \\
\text { OF ABSTRACT } \\
\text { Unclassified }\end{array}$ \\
\hline
\end{tabular}

